\title{
Molecular cytogenetic characterization of small supernumerary marker 15 in infertile male: A case report
}

\author{
MEILING SUN ${ }^{1,2}$, RUIXUE WANG ${ }^{1,2}$, HONGGUO ZHANG $^{1,2}$, YUTING JIANG ${ }^{1,2}$, \\ JING HE ${ }^{1,2}$, SHIBO $\mathrm{LI}^{3}$ and RUIZHI LIU ${ }^{1,2}$ \\ ${ }^{1}$ Center for Reproductive Medicine and Center for Prenatal Diagnosis, The First Hospital, Jilin University; \\ ${ }^{2}$ Jilin Engineering Research Center for Reproductive Medicine and Genetics, Jilin University, Changchun, Jilin 130021, \\ P.R. China; ${ }^{3}$ Department of Pediatrics, University of Oklahoma Health Sciences Center, Oklahoma, OK 73104, USA
}

Received June 4, 2019; Accepted January 6, 2020

DOI: $10.3892 /$ etm.2020.8542

\begin{abstract}
Small supernumerary marker chromosomes (sSMCs) are defined as structurally abnormal chromosomes that may be detected pre- or postnataly in patients with developmental and/or mental retardation or infertility. sSMC on chromosome 15 accounts for the highest proportion of all sSMCs and may be detected in subfertile individuals. The present study reports the case of a male patient with oligoasthenoteratozoospermia and an sSMC. The sSMC was identified and characterized according to G-banding analysis, chromosomal microarray analysis (CMA) and fluorescence in situ hybridization (FISH) analysis. Chromosomal karyotype analysis suggested that the patient presented with 47,XY,+mar. CMA was used to characterize the sSMC, which revealed a 0.44-Mb microduplication in 6q25.3q26. Subsequently, FISH using centromere-specific probes for chromosomes 13/21, $14 / 22$ and 15 was applied to identify the origin of the sSMC, which was finally determined to be inverted duplicated(15) (q11.2). It was hypothesized that heterochromatin in the sSMC is responsible for the patient's fertility problem. The presence of heterochromatin may disrupt regular meiosis, thereby affecting normal spermatogenesis. Impaired spermatogenesis in infertile males with an sSMC derived from chromosome 15 was also reviewed by searching published literature and the sSMC database (http://ssmc-tl.com/sSMC.html). For patients
\end{abstract}

Correspondence to: Dr Ruizhi Liu, Center for Reproductive Medicine and Center for Prenatal Diagnosis, The First Hospital, Jilin University, 71 Xinmin Street, Changchun, Jilin 130021, P.R. China E-mail: 1rz410@126.com

Abbreviations: sSMC, small supernumerary marker chromosome; OAT, oligoasthenoteratozoospermia; CMA, chromosome microarray analysis; FISH, fluorescence in situ hybridization; OMIM, Online Mendelian Inheritance in Man

Key words: male infertility, small supernumerary marker chromosomes, oligoasthenoteratozoospermia, fluorescence in situ hybridization, chromosomal microarray analysis, intracytoplasmic sperm injection with low sperm parameters and complete absence of spermatozoa in the ejaculate, including infertile males with an sSMC with spermatozoa, intracytoplasmic sperm injection is considered as an effective assisted reproductive technique. It may be concluded that molecular cytogenetic techniques are critical tools for delineating sSMCs in infertile males and may be beneficial in identifying $\mathrm{SSMC}$ carriers to ensure they receive clinical genetic counseling.

\section{Introduction}

Infertility is characterized by failure to establish a clinical pregnancy after 12 months of regular and unprotected sexual intercourse. In China, the frequency of infertility is estimated to be $15-20 \%$ and male factors account for $50 \%$ among infertile couples $(1,2)$. Male infertility, occurs in a clinically population and is influenced by factors including hormone status, age, exercise, obesity, infectious disease and immunological or psychological factors. In addition, various genetic impairments are associated with problems of fertility, including azoospermia factor deletion, mutations in the cystic fibrosis transmembrane conductance regulator and numerical/structural chromosomal abnormalities $(3,4)$.

Small supernumerary marker chromosomes (sSMCs) are defined as structurally abnormal chromosomes that cannot be clearly characterized by conventional cytogenetic banding (5). While the incidence rate of sSMCs is $0.3-0.5 / 1,000$ in the normal population, this occurrence is up to $0.125 \%$ in patients with fertility problems, with a male-to-female ratio of 7.5:1 (1). sSMCs may present as various forms, including inverted duplicated (inv dup), complex rearranged, minute, ring or neocentric chromosomes (6). Most sSMCs result from short arms and pericentric regions of acrocentric chromosomes, among which sSMC on chromosome 15 [sSMC(15)] is the most common (7-9). To date, the genotype-phenotype association between sSMCs and male infertility has remained elusive. Therefore, more evidence is required to determine this association.

The current study presents the case of a male patient with oligoasthenoteratozoospermia (OAT) and sSMC(15). A literature review on sSMC(15)-associated spermatozoa as a cause of infertility in males was also performed. 


\section{Case report}

A 38-year-old Chinese male was referred to the Center for Reproductive Medicine and the Center for Prenatal Diagnosis of the First Hospital of Jilin University (Changchun, China) for consultation for infertility after 1 year of regular unprotected sexual intercourse with no resulting pregnancy in November 2017. No apparent abnormalities were observed in this patient, except for infertility. A series of routine clinical examinations were performed. Semen analysis indicated that the patient had OAT according to the World Health Organization guidelines (10). Reproductive hormone levels were as follows: Luteinizing hormone, $4.65 \mathrm{mIU} / \mathrm{ml}$ (normal range, 1.7-8.5 mIU/ml); follicle-stimulating hormone, $4.95 \mathrm{mIU} / \mathrm{ml}$ (normal range, $1.5-12.4 \mathrm{mIU} / \mathrm{ml}$ ); estradiol, $14.3 \mathrm{pg} / \mathrm{ml}$ (normal range, $28-248 \mathrm{pg} / \mathrm{ml}$ ); testosterone, $6.46 \mathrm{nmol} / \mathrm{l}$ (normal range, 9.9-27.8 nmol/l); and prolactin, $149.2 \mu \mathrm{IU} / \mathrm{ml}$ (normal range, 86-258 $\mu \mathrm{IU} / \mathrm{ml}$ ). All normal ranges were based on data provided by the Center for Reproductive Medicine and Center for Prenatal Diagnosis, The First Hospital, Jilin University. The present study was approved by the Ethics Committee of the First Hospital of Jilin University (Changchun, China; permit no. 2017-402). Informed written consent was obtained from the patient for publication of this case report and accompanying images.

G-banding analysis was performed according to standard procedures on peripheral blood cells of the patient (11). A total of 50 metaphase cells were analyzed. The karyotype was described according to the International System for Human Cytogenetic Nomenclature 2016 nomenclature (12). The result suggested that the patient had a non-mosaic abnormal karyotype of 47,XY,+mar (Fig. 1).

Chromosomal microarray analysis (CMA) was performed on peripheral blood samples of the patient to analyze whole-genome copy number variations and to detect heterozygous deletion by the CytoScan $750 \mathrm{~K}$ array (Affymetrix; Themo Fisher Scientific, Inc.). This method detects human genomic DNA copy number variations and loss of heterozygosity with $\geq 50$ probe labels and $\geq 200$-kb resolution, covering 22 pairs of autosomal and sex chromosomes. Thresholds for genome-wide screening were set at $\geq 200 \mathrm{~kb}$ for gains, $\geq 100 \mathrm{~kb}$ for losses and $\geq 10 \mathrm{Mb}$ for loss of heterozygosity. The detected copy number variations were comprehensively evaluated through the published literature and public databases, including DECIPHER v9.28 (https://decipher.sanger.ac.uk/), the database of genomic variants and Online Mendelian Inheritance in Man (OMIM; https://www.ncbi.nlm.nih.gov/omim; accessed June 1st 2019). The genomic coordinates were based on the GRCh37/hg19 build of the human reference genome (13). A $0.44 \mathrm{Mb}$ gain in $6 \mathrm{q} 25.3 \mathrm{q} 26$ was detected, which revealed $\operatorname{arr}[\mathrm{hg} 19] 6 \mathrm{q} 25.3 \mathrm{q} 26(160,569,492-161,010,647) \times 3$ (Fig. 2).

Fluorescence in situ hybridization (FISH) was used to further identify the origin of the sSMC. Specific probes for chromosomes 13/21, 14/22 and 15 were used to investigate the origin of the sSMC. The majority of the probes used in the present study were commercial probes, including chromosomes 13/21, 14/22 centromere probes. The D13Z1 $\alpha$-satellite probe was located at 13p11.1-q11.1 (cat no. LPE 013R/G-A; spectrum: Green), the $\alpha$-satellite D21Z1 probe was located at 21p11.1-q11.1 (cat no. LPE 013R/G-A; spectrum: Green), the $\alpha$-satellite D14Z1 probe was located at 14p11.1-q11.1 (cat

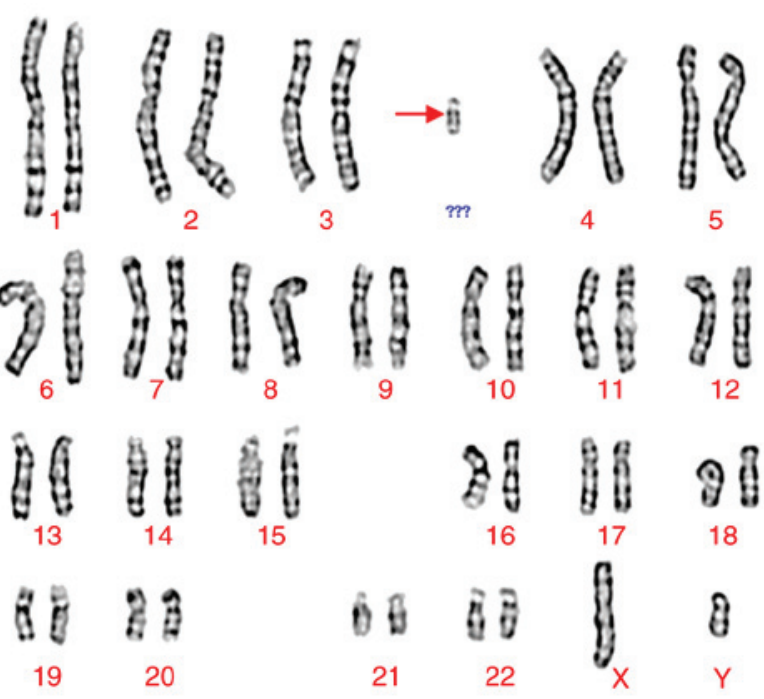

Figure 1. G-banding results. G-banding indicated the chromosomal karyotype 47,XY,+mar. The red arrow indicates karyotype 47,XY,+mar.

no. LPE 014R/G-A; spectrum: Red), the $\alpha$-satellite D22Z1 probe was located at 22p11.1-q11.1 (cat no. LPE 014R/G-A; spectrum: Red). The satellite III D15Z1 probe was located at 15p11.2 (spectrum: Green), the small nuclear ribonucleoprotein polypeptide N Prader-Willi/Angelman probe (SNRPN) was located at 15q11-q13 (spectrum: Orange) and the PML probe was located at 15q24 (spectrum: Orange) (14). All probes were supplied by Cytocell Technologies Ltd. FISH indicated that the sSMC was positive twice for D15Z1 signals, which were located at 15p11.2, but negative for the probes SNRPN (15q11-13) and PML (15q24) (Fig. 3).

These results indicated that the marker chromosome was sSMC(15), which consisted of two short arms, two centromeres and a pericentric region. The sSMC was finally identified as inv dup(15)(q11.2). No chromosomal analysis was performed in the proband's parents to determine whether the sSMC of the proband was de novo or inherited. According to the follow-up outcomes, the patient will pursue the reproductive option of artificial insemination with donor semen.

The present study focused on infertile patients with sSMC(15), commonly presenting with impairment of spermatogenesis and no apparent abnormalities. Based upon this selection criterion, a systematic literature search was conducted by means of a Pubmed literature search (http://www.ncbi.nlm. nih.gov/pubmed/; accessed May 16th 2019) using relevant terms and their combinations [sSMC(15) with male infertility, marker chromosome 15 with male infertility and sSMC(15) with spermatogenesis; Table I] (15-19), and by searching the sSMC database (http://ssmc-tl.com/sSMC.html; accessed May 16th 2019). It was attempted to establish an association between non-mosaic sSMC(15) and impairment of spermatogenesis in males. All cases are listed in Table I and they were divided into four groups as follows: i) OAT; ii) oligospermia; iii) azoospermia and iv) cryptozoospermia, which are common manifestations of spermatozoa in infertile males (20). It was revealed that in $90 \%$ (19/21) of cases, sSMCs were described as inv dup(15) and involved the centromere of chromosome 15. In addition, OAT and severe OAT accounted for $47 \%$, followed by oligospermia (24\%), azoospermia (19\%) and 


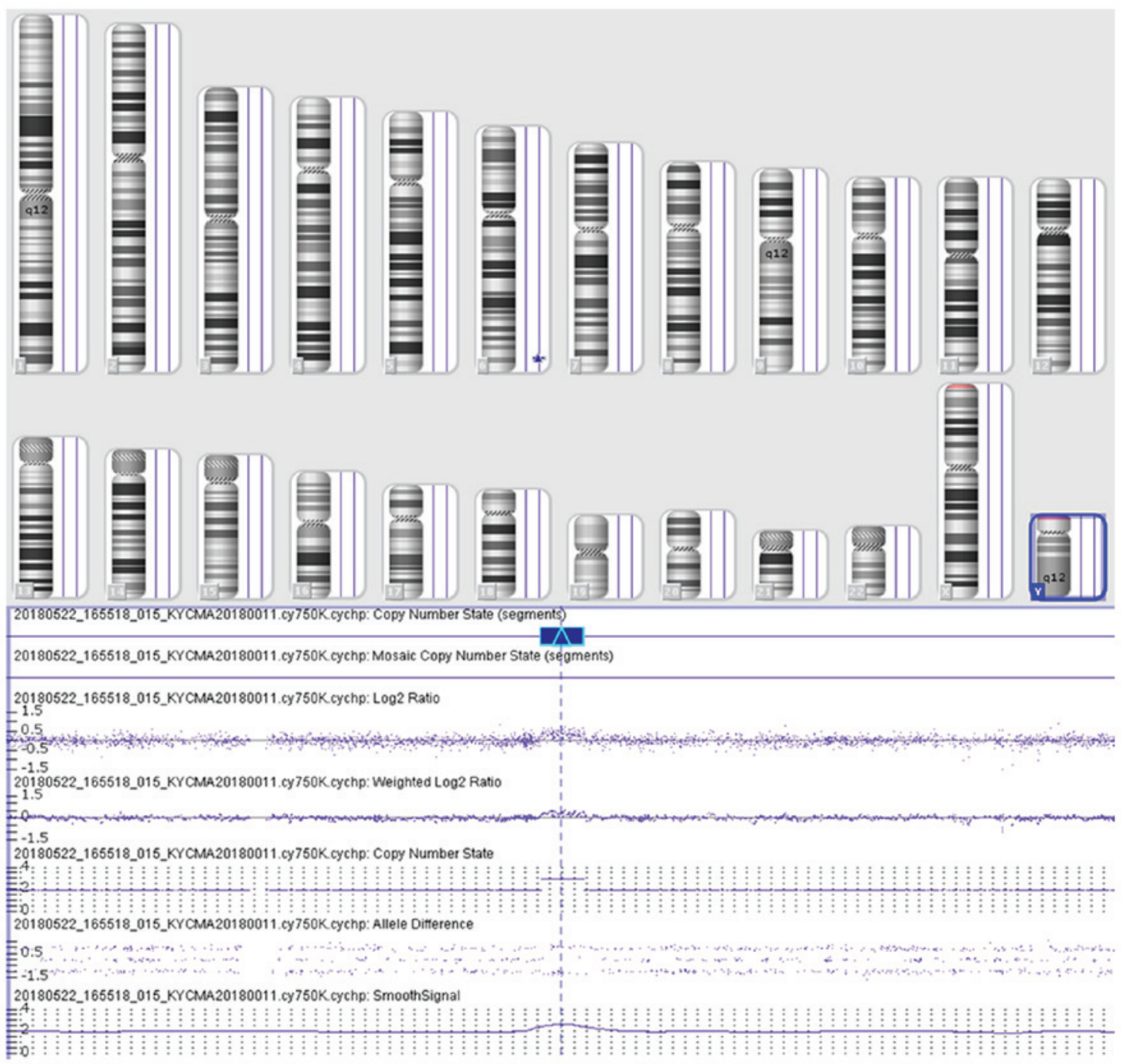

Figure 2. Analysis of the small supernumerary marker chromosomes of the patient. Small supernumerary marker chromosome analysis revealed a $0.44-\mathrm{Mb}$ interstitial duplication at 6q25.3q26, which was described as arr[hg19] 6q25.3q26(160,569,492-161,010,647)x3.

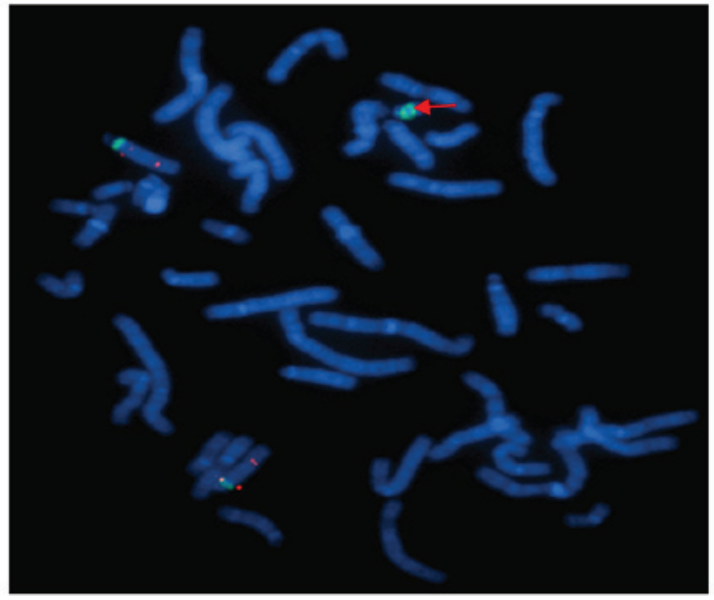

Figure 3. Fluorescence in situ hybridization. Fluorescence in situ hybridization indicated that the small supernumerary marker chromosome was positive for D15Z1 (arrow; magnification, x1,000).

cryptozoospermia (10\%) (Fig. 4). In addition, no co-morbidities associated with $\mathrm{SSMC}(15)$ were identified in any or all of these
4 groups. Furthermore, multivariate statistical analyses were performed but no significant associations were identified due to the lack of age specifications in the azoospermia group. In conclusion, the effect of sSMC(15) on abnormal spermatogenesis requires confirmation by further studies.

\section{Discussion}

The present study reported on a male patient with non-mosaic sSMC(15) who presented with OAT but had no other apparent abnormalities. Cytogenetic analysis of the proband indicated that the karyotype was $47, \mathrm{XY},+$ mar, while subsequent CMA results further indicated a $0.44-\mathrm{Mb}$ gain in $6 \mathrm{q} 25.3 \mathrm{q} 26$. FISH results indicated positive D15Z1 signals twice, which indicated that the sSMC originated from chromosome 15. The sSMC was finally identified as inv $\operatorname{dup}(15)(\mathrm{q} 11.2)$.

sSMCs are defined as structurally abnormal chromosomes that may be detected in patients with developmental and/or mental retardation and infertility, and in prenatal or postnatal cases (21). The genotype-phenotype correlation of sSMC is currently complex and diverse due to its origin, size and constitution (14). Euchromatic sSMCs, encompassing gene 
Table I. Summary of male sSMC(15) carriers with spermatogenesis impairment and no apparent abnormalities based upon the literature review and the sSMC database.

\begin{tabular}{|c|c|c|c|c|c|}
\hline Case no. & $\begin{array}{l}\text { Age at diagnosis } \\
\text { (years) }\end{array}$ & GTG result & Final result of the sSMC & Diagnosis & (Refs.) \\
\hline 1 & 38 & $47, \mathrm{XY},+\operatorname{mar}[100 \%]$ & $\operatorname{inv} \operatorname{dup}(15)(q 11.2)$ & OAT & Present case \\
\hline 2 & Adult & $47, \mathrm{XY},+\operatorname{mar}[100 \%]$ & $\operatorname{inv} \operatorname{dup}(15)(\mathrm{q} 11)$ & Severe OAT & (15) \\
\hline 3 & 39 & $47, \mathrm{XY},+\operatorname{mar}[100 \%]$ & $\min (15)(\mathrm{p} 11 \rightarrow \mathrm{q} 11)$ & Oligospermia & (16) \\
\hline 4 & 34 & $47, \mathrm{XY},+\operatorname{mar}[100 \%]$ & $\operatorname{inv} \operatorname{dup}(15)(q 11.1)$ & OAT & (17) \\
\hline 5 & 41 & $47, \mathrm{XY},+\operatorname{mar}[100 \%]$ & $\operatorname{inv} \operatorname{dup}(15)(q 11.1)$ & OAT & (18) \\
\hline 6 & 39 & $47, \mathrm{XY},+\operatorname{mar}[100 \%]$ & $\operatorname{inv} \operatorname{dup}(15)(q 11.1)$ & OAT & (17) \\
\hline 7 & 37 & $47, \mathrm{XY},+\operatorname{mar}[100 \%]$ & $\operatorname{inv} \operatorname{dup}(15)(q 11.2)$ & Oligospermia & (17) \\
\hline 8 & 30 & $47, \mathrm{XY},+\operatorname{mar}[100 \%]$ & $\operatorname{inv} \operatorname{dup}(15)(q 11.2)$ & OAT & (17) \\
\hline 9 & 43 & $47, \mathrm{XY},+\operatorname{mar}[100 \%]$ & $\operatorname{inv} \operatorname{dup}(15)(q 11.2)$ & Cryptozoospermia & (17) \\
\hline 10 & Adult & $47, \mathrm{XY}+\operatorname{mar}[100 \%]$ & $\begin{array}{c}\min \text { or } \operatorname{mar}(15) \\
(\text { pter } \rightarrow q 11.2:)\end{array}$ & Oligospermia & (17) \\
\hline 11 & 33 & $47, \mathrm{XY},+\operatorname{mar}[100 \%]$ & $\operatorname{inv} \operatorname{dup}(15)(q 11.2 \sim q 13)$ & $\begin{array}{l}\text { Oligospermia, unilateral } \\
\text { cryptorchidism }\end{array}$ & (19) \\
\hline $12-14$ & Postnatal & $47, \mathrm{XY},+\operatorname{mar}[100 \%]$ & inv dup(15)(q11.1) & Azoospermia & (17) \\
\hline 15 & Postnatal & $47, \mathrm{XY},+\operatorname{mar}[100 \%]$ & $\operatorname{inv} \operatorname{dup}(15)(q 11.1)$ & OAT, seminoma & (17) \\
\hline 16 & Postnatal & $47, \mathrm{XY},+\operatorname{mar}[100 \%]$ & $\operatorname{inv} \operatorname{dup}(15)(q 11.1)$ & Azoospermia & (17) \\
\hline 17 & Postnatal & $47, \mathrm{XY},+\operatorname{mar}[100 \%]$ & inv dup(15) & OAT & (17) \\
\hline 18 & Postnatal & $47, \mathrm{XY},+\operatorname{mar}[100 \%]$ & $\operatorname{inv} \operatorname{dup}(15)$ & Oligospermia & (17) \\
\hline 19 & Postnatal & $47, \mathrm{XY},+\operatorname{mar}[100 \%]$ & $\operatorname{inv} \operatorname{dup}(15)$ & Several OATs & (17) \\
\hline 20 & Postnatal & $47, \mathrm{XY},+\operatorname{mar}[100 \%]$ & $\operatorname{inv} \operatorname{dup}(15)$ & Several OATs & (17) \\
\hline 21 & Postnatal & $47, \mathrm{XY},+\operatorname{mar}[100 \%]$ & $\operatorname{inv} \operatorname{dup}(15)$ & Cryptozoospermia & (17) \\
\hline
\end{tabular}

n.a., not available; OAT, oligoasthenoteratozoospermia; sSMC, small supernumerary marker chromosomes; dup, duplication; inv, inverted; min, minute; mar, marker chromosome; GTG, G-Banding using Trypsin and Giemsa.

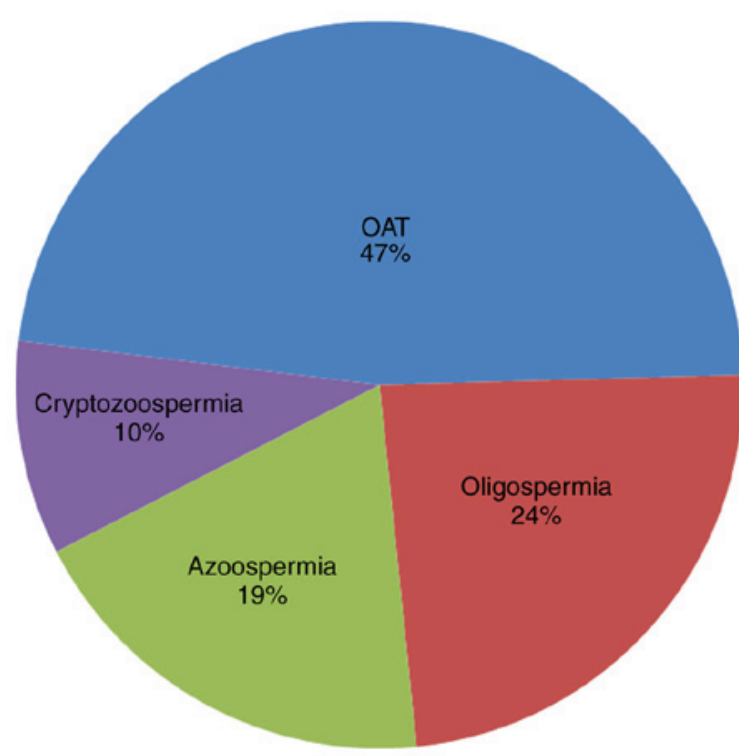

Figure 4. Small supernumerary marker chromosome 15 distribution. Distribution of small supernumerary marker chromosome 15 in males with fertility problems with aberrant semen parameters. OAT, oligoasthenoteratozoospermia.

dosage-sensitive genes, may be harmful, while sSMCs only containing heterochromatin are mostly harmless (22). The clinical phenotypes of sSMC(15) are diverse due to the existence of chromosomal euchromatin/heterochromatin. When sSMC(15) contains 15q euchromatin and the Prader-Willi syndrome/Angelman syndrome critical region, the relevant clinical manifestations include developmental retardation, intellectual disability, epilepsy and autistic behavior. By contrast, when sSMC(15) only contains heterochromatin, it is considered harmless regarding clinical outcomes, although exceptions have been recorded (23). Of note, sSMCs may lead to only fertility problems without the appearance of any additional clinical symptoms (1). Liehr and Hamid Al-Rikabi (4) pointed out that most SSMCs in infertile males were derived from acrocentric chromosomes, particularly sSMC(15), which accounted for up to $40 \%$ of all sSMCs. Patients with sSMC(15) are generally clinically normal, while the risk of oligo- or azoospermia is increased in infertile males, which may affect spermatogenesis $(24,25)$. Further research is required on sSMC(15) due to the complex effect of the origin, size and mosaicism of this sSMC on clinical phenotypes $(25,26)$.

In the present study, the patient was diagnosed with OAT with the karyotype 47,XY,+mar and the sSMC was further identified as inv dup(15)(q11.2) by CMA and FISH analysis. Table I obtained by searching for relevant cases showed that sSMC(15) was related to OAT, but the mechanism of $\mathrm{SSMC}(15)$ on abnormal spermatogenesis needed further research. Molecular cytogenetic techniques have critical roles in the characterization 
of sSMCs and detection of genomic copy number variations, chromosomal breakpoints and the genes involved $(4,14)$. In the present study, CMA analysis detected a $0.44-\mathrm{Mb}$ interstitial duplication in 6q25.3q26, which led to $\operatorname{arr}[\mathrm{hg} 19] 6 \mathrm{q} 2$ $5.3 q 26(160,569,492-161,010,647) \times 3$. This region included solute carrier family 22 member 1 (SLC22A1; OMIM:602607), SLC22A2 (OMIM:602608), SLC22A3 (OMIM:604842) and lipoprotein A (LPA; OMIM:152200) genes. Mutation of LPA is associated with susceptibility to coronary artery disease (27). SLC22A1, SLC22A2 and SLC22A3 are members of cation transporter genes that are located in a cluster on chromosome 6. Production of SLC22A1 is the major organic cation uptake system in hepatocytes (28). SLC22A2 may mediate the first step of tubular secretion of most positively charged substances (29) and SLC22A3 may have a significant role in the disposition of cationic neurotoxins and neurotransmitters in the brain $(30,31)$. The duplications of these genes, likely benign variations, may not be responsible for the spermatogenesis disorder in the infertile patient of the present study.

Certain hypotheses may explain the reason for infertility in the present case. First, there might be an association between the nucleolar organizer region (NOR) and meiotic abnormalities. The NOR is located on the short arms of human acrocentric chromosomes and the chromosomal context of NOR has a critical role in nuclear biology (32). Additional NOR activity beyond an optimal threshold resulting from marker chromosomes may predispose to meiotic disturbances (33). Furthermore, an imbalance caused by increased heterochromatin may have a negative effect on the maturation of germ cells during meiosis (34). In addition, an interchromosomal effect may increase the risk in chromosomal non-disjunction of aneuploid sperm during meiosis, which may affect the nuclear structure of sperm (35). An interchromosomal effect resulting from the presence of sSMCs is likely lead to infertility to a certain extent (1).

Although FISH analysis suggested that the breakpoint of inv dup(15) was located between 15 p11.2 and 15q11-13, the exact breakpoint and the amount of extra euchromatin or heterochromatin was not identified using the SNRPN probe in the present case. Previous studies have indicated that males with maternal-inherited sSMCs and females with paternal-inherited sSMCs were inclined to be infertile $(1,3,25)$. However, the present study did not determine whether the presence of sSMC(15) in the proband was parentally inherited or de novo. Intracytoplasmic sperm injection may help infertile males with an sSMC and spermatozoa obtain offspring. Pre-implantation genetic diagnosis may detect sSMCs in pre-implantation embryos through specific probes, and normal embryos may be selected for transfer following in vitro fertilization $(36,37)$. Regardless of what choice has been made, prenatal diagnosis is still necessary after the establishment of pregnancy. In addition, explorative attempts have been made in pre-implantation human embryos through targeted DNA excision technologies, including clustered regularly interspaced short palindromic repeats. However, off-target effects resulting from cutting non-targeted genes when using DNA excision technologies and other adverse effects on the developing embryo due to the techniques applied are major problems in the process and the issues regarding medical ethics should not be ignored (38).

In conclusion, the present case study reported on a male patient with OAT and an sSMC derived from acrocentric chromosome 15, which was identified by karyotype analysis, CMA and FISH analysis. The present study not only underlines the significance of the genotype-phenotype association of sSMC(15) and male infertility, but also adds evidence to the diversity in the quality of spermatozoa associated with sSMC(15). For infertile sSMC carriers with spermatozoa, application of pre-implantation genetic diagnosis may have a role in selecting normal embryos to a certain extent, which may be beneficial for achieving offspring for such patients. Furthermore, comprehensive evaluation of fertility and genetic counseling is warranted in advance and prenatal diagnosis after pregnancy should not be neglected.

\section{Acknowledgements}

Not applicable.

\section{Funding}

This work was supported by the National Key Research and Development Program of China (grant no. 2016YFC1000601).

\section{Availability of data and materials}

The datasets used and/or analyzed during the study are available from the corresponding author on reasonable request.

\section{Authors' contributions}

MS obtained the clinical information, collected data from the literature and wrote the first draft of the manuscript. RW and $\mathrm{HZ}$ collected patient data and participated in the analysis and interpretation of data. YJ and $\mathrm{JH}$ participated in the analysis and interpretation of data. SL and RL conceived and designed the study. SL and RL reviewed the manuscript and were involved in its critical revision prior to submission. All authors read and approved the final manuscript.

\section{Ethics approval and consent to participate}

The study was approved by Medical Ethics Committee of The First Hospital of Jilin University (permit no. 2017-402). The patient provided written informed consent to participate in this study.

\section{Patient consent for publication}

The patient provided written informed consent for the publication of the present case report.

\section{Competing interests}

The authors declare that they have no competing interests.

\section{References}

1. Armanet N, Tosca L, Brisset S, Liehr T and Tachdjian G: Small supernumerary marker chromosomes in human infertility. Cytogenet Genome Res 146:100-108, 2015.

2. Neto FT, Bach PV, Najari BB, Li PS and Goldstein M: Genetics of Male Infertility. Curr Urol Rep 17: 70, 2016. 
3. Manvelyan M, Riegel M, Santos M, Fuster C, Pellestor F, Mazaurik ML, Schulze B, Polityko A, Tittelbach H, Reising-Ackermann G, et al: Thirty-two new cases with small supernumerary marker chromosomes detected in connection with fertility problems: Detailed molecular cytogenetic characterization and review of the literature. Int J Mol Med 21: 705-714, 2008.

4. Liehr T and Hamid Al-Rikabi AB: Impaired spermatogenesis due to small supernumerary marker chromosomes: The reason for infertility is only reliably ascertainable by cytogenetics. Sex Dev, 2018 (Epub ahead of print).

5. Wang H, Wang T, Yang N, He Y, Chen L, Hong L, Shao X, Li H, Zhu $\mathrm{H}$ and $\mathrm{Li} \mathrm{H}$ : The clinical analysis of small supernumerary marker chromosomes in 17 children with mos 45,X/46,X,+mar karyotype. Oncol Lett 13: 4385-4389, 2017.

6. Plaja A, Lloveras E, Martinez-Bouzas C, Barreña B, Del Campo M, Fernández A, Herrero M, Barranco L, Palau N, López-Aríztegui MA, et al: Trisomy 18 p caused by a supernumerary marker with a chromosome 13/21 centromere: A possible recurrent chromosome aberration. Am J Med Genet A 161A: 2363-2368, 2013.

7. Guediche N, Tosca L and Kara Terki A: Array comparative genomic hybridization analysis of small supernumerary marker chromosomes in human infertility. Reprod Biomed Online 24: 72-82, 2012.

8. Quinonez SC, Gelehrter TD and Uhlmann WR: A Marfan syndrome-like phenotype caused by a neocentromeric supernumerary ring chromosome 15. Am J Med Genet A 173: 268-273, 2017.

9. Crolla JA, Youings SA, Ennis S and Jacobs PA: Supernumerary marker chromosomes in man: Parental origin, mosaicism and maternal age revisited. Eur J Hum Genet 13: 154-160, 2005.

10. WHO Laboratory Manual for the Examination and Processing of Human Semen. 5th edition. World Health Organization, Geneva, 2010.

11. Zhang H, Wang R, Li L, Jiang Y, Zhang H and Liu R: Clinical feature of infertile men carrying balanced translocations involving chromosome 10: Case series and a review of the literature. Medicine (Baltimore) 97: e0452, 2018.

12. McGowan-Jordan J, Simons A and Schmid M: ISCN (2016) An International System for Human Cytogenetic Nomenclature. Basel, Switzerland: Karger, 2016.

13. Hochstenbach R, Nowakowska B, Volleth M, Ummels A, Kutkowska-Kaźmierczak A, Obersztyn E, Ziemkiewicz K, Gerloff C, Schanze D, Zenker M, et al: Multiple small supernumerary marker chromosomes resulting from maternal meiosis i or ii errors. Mol Syndromol 6: 210-221, 2016

14. Sun M, Zhang H, Li G, Guy CJ, Wang X, Lu X, Gong F, Lee J, Hassed S and Li S: Molecular characterization of 20 small supernumerary marker chromosome cases using array comparative genomic hybridization and fluorescence in situ hybridization. Sci Rep 7: 10395, 2017.

15. Peschka B, Leygraaf J, Van der Ven K, Montag M, Schartmann B, Schubert R, van der Ven H and Schwanitz G: Type and frequency of chromosome aberrations in 781 couples undergoing intracytoplasmic sperm injection. Hum Reprod 14: 2257-2263, 1999.

16. Cetin Z, Berker Karaüzüm S, Yakut S, Mihçi E, Baumer A, Wey E, Taçoy S, Bağci G and Lüleci G: M-FISH applications in clinical genetics. Genet Couns 16: 257-268, 2005.

17. Liehr T: Small supernumerary marker chromosomes detected in connection with infertility. Zhonghua Nan Ke Xue 20: 771-780, 2014.

18. Paetzold U, Schwanitz G, Schubert R, van der Ven K and Montag M: Sperm analyses, genetic counseling and therapy in an infertile carrier of a supernumerary marker chromosome 15 Adv Med Sci 51: 31-35, 2006.

19. Vulcani-Freitas TM, Gil-da-Silva-Lopes VL, Varella-Garcia M and Maciel-Guerra AT: Infertility and marker chromosomes: Application of molecular cytogenetic techniques in a case of inv dup(15). J Appl Genet 47: 89-91, 2006.

20. Magdi Y, Darwish E, Elbashir S, Majzoub A and Agarwal A: Effect of modifiable lifestyle factors and antioxidant treatment on semen parameters of men with severe oligoasthenoteratozoospermia. Andrologia: Nov 10, 2017 (Epub ahead of print) doi: 10.1111/and.12694.
21. Liehr T and Weise A: Frequency of small supernumerary marker chromosomes in prenatal, newborn, developmentally retarded and infertility diagnostics. Int J Mol Med 19: 719-731, 2007.

22. Liehr T and Kosyakova N: Small supernumerary marker chromosomes (sSMC)-what about the genotype-phenotype correlation? Tsitologiia 55: 165-166, 2013.

23. Battaglia A: The inv dup (15) or idic (15) syndrome (Tetrasomy 15q). Orphanet J Rare Dis 3: 30, 2008.

24. Cotter PD, Ko E, Larabell SK, Rademaker AW and Martin RH: Segregation of a supernumerary del(15) marker chromosome in sperm. Clin Genet 58: 488-492, 2000.

25. Koç A, Onur SO, Ergün MA and Perçin EF: Supernumerary marker chromosome 15 in a male with azoospermia and open bite deformity. Asian J Androl 11: 617-622, 2009.

26. Liehr T: Small supernumerary marker chromosomes-an update. Mol Cytogenet: Jan 21, 2014 (Epub ahead of print). doi: 10.1186/17558166-7-S1-I11

27. Clarke R, Peden JF, Hopewell JC, Kyriakou T, Goel A, Heath SC, Parish S, Barlera S, Franzosi MG, Rust S, et al: Genetic variants associated with Lp(a) lipoprotein level and coronary disease. New Eng J Med 361: 2518-2528, 2009.

28. Gründemann D, Gorboulev V, Gambaryan S, Veyhl M and Koepsell H: Drug excretion mediated by a new prototype of polyspecific transporter. Nature 372: 549-552, 1994.

29. Hoermann S, Gai Z, Kullak-Ublick GA and Visentin M: Plasma membrane cholesterol regulates the allosteric binding of 1-methyl-4-phenylpyridinium to organic cation transporter 2 (SLC22A2). J Pharmacol Exp Ther 372: 46-53, 2020.

30. Gründemann D, Schechinger B, Rappold GA and Schömig E: Molecular identification of the corticosterone-sensitive extraneuronal catecholamine transporter. Nat Neurosci 1: 349-351, 1998.

31. Wu X, Huang W, Ganapathy ME, Wang H, Kekuda R, Conway SJ, Leibach FH and Ganapathy V: Structure, function, and regional distribution of the organic cation transporter OCT3 in the kidney. Am J Physiol Renal Physiol 279: F449-F458, 2000.

32. Mangan H, Gailín MO and McStay B: Integrating the genomic architecture of human nucleolar organizer regions with the biophysical properties of nucleoli. FEBS J 284: 3977-3985, 2017.

33. Martín-Lucas MA, Pérez-Castillo A and Abrisqueta JA: Infertility associated with two accessory bisatellited chromosomes. Hum Genet 73: 133-136, 1986.

34. Gentile M, Susca F, Resta N, Stella A, Cascone A and Guanti G: Infertility in carriers of two bisatellited marker chromosomes. Clin Genet 44: 71-75, 1993.

35. Kirkpatrick G, Ren H, Liehr T, Chow V and Ma S: Meiotic and sperm aneuploidy studies in three carriers of Robertsonian translocations and small supernumerary marker chromosomes. Fertil Steril 103: 1162-1169.e7, 2015.

36. Perrin A, Nguyen MH, Delobel B, Guéganic N, Basinko A, Le Bris MJ, Douet-Guilbert N, De Braekeleer M and Morel F: Characterization and meiotic segregation of a supernumerary marker chromosome in sperm of infertile males: Case report and literature review. Eur J Med Genet 55: 743-746, 2012.

37. Oracova E, Musilova P, Kopecna O, Rybar R, Vozdova M, Vesela K and Rubes J: Sperm and embryo analysis in a carrier of supernumerary inv dup(15) marker chromosome. J Androl 30: 233-239, 2009.

38. Ranisch R: Germline genome editing versus preimplantation genetic diagnosis: Is there a case in favour of germline interventions? Bioethics 34: 60-69, 2020

This work is licensed under a Creative Commons Attribution-NonCommercial-NoDerivatives 4.0 International (CC BY-NC-ND 4.0) License. 